\title{
Surgical Approaches to Epicardial Pacemaker Placement: Does Pocket Location Affect Lead Survival?
}

\author{
Brian J. Lichtenstein · David P. Bichell • \\ Dana M. Connolly • John J. Lamberti • \\ Suzanne M. Shepard $\cdot$ Stephen P. Seslar
}

Received: 22 February 2010/ Accepted: 14 July 2010/Published online: 6 August 2010

(c) The Author(s) 2010. This article is published with open access at Springerlink.com

\begin{abstract}
Permanent cardiac pacing in pediatric patients presents challenges related to small patient size, complex anatomy, electrophysiologic abnormalities, and limited access to cardiac chambers. Epicardial pacing currently remains the conventional technique for infants and patients with complex congenital heart disease. Pacemaker lead failure is the major source of failure for such epicardial systems. The authors hypothesized that a retrocostal surgical approach would reduce the rate of lead failure due to fracture compared with the more traditional subrectus and subxiphoid approaches. To evaluate this hypothesis, a retrospective chart review analyzed patients with epicardial pacemaker systems implanted or followed at Rady Children's Hospital San Diego between January 1980 and May 2007. The study cohort consisted of 219 patients and a total of 620 leads with epicardial pacemakers. Among these patients, $84 \%$ had structural congenital heart disease,
\end{abstract}

B. J. Lichtenstein · J. J. Lamberti

University of California, San Diego School of Medicine,

La Jolla, CA, USA

e-mail: brianlichtenstein@gmail.com

D. P. Bichell

Department of Cardiac Surgery, Vanderbilt University School of Medicine, Vanderbilt Children's Hospital, Vanderbilt

University Medical Center, Nashville, TN, USA

D. M. Connolly · J. J. Lamberti - S. M. Shepard Children's Heart Institute, Rady Children's Hospital-San Diego, University of California, 3030 Children's Way,

San Diego, CA 92123, USA

\section{S. P. Seslar $(\square)$}

Department of Pediatrics, Seattle Children's Hospital, University of Washington School of Medicine,

4800 Sand Point Way, M/S G-0035, Seattle, WA 98105, USA

e-mail: stephen.seslar@seattlechildrens.org and $45 \%$ were younger than 3 years at time of the first implantation. The estimated lead survival was $93 \%$ at 2 years and $83 \%$ at 5 years. The majority of leads failed due to pacing problems (54\%), followed by lead fracture (31\%) and sensing problems (14\%). When lead failure was adjusted for length of follow-up period, no significant differences in the rates of failure by pocket location were found.

Keywords Congenital heart disease - Electrophysiology · Epicardial · Pacemaker

Permanent cardiac pacing in pediatric patients presents many challenges related to small patient size, complex anatomy, electrophysiologic abnormalities, and limited access to cardiac chambers $[1,7,10]$. Although many adolescent patients are well served by transvenous pacemakers, epicardial pacing currently remains the conventional technique for infants and those with complex congenital heart disease $[9,10]$. Epicardial pacemaker leads must be affixed to the outer surface of the heart by direct application in the operating room. Because of the complex cardiac anatomy, lack of pediatric-specific devices, and variable surgeon training and experience, a range of surgical techniques have evolved [14]. These techniques include different surgical approaches (partial or full sternotomy, subxyphoid, thoracotomy), generator pocket location (retrocostal, subrectus, subxyphoid), and various lead fixation methods.

Findings have shown that epicardial lead placement is a risk factor for lead failure compared with transvenously placed leads $[6,11]$. Historically, the pacemaker generator pocket has been formed in the abdominal wall within the rectus abdominus muscle sheath, typically at the level of the umbilicus. At the institution where this study was conducted, this approach is termed subrectus. 
In 1999, surgeons at Rady Children's Hospital, San Diego, California began implanting generators closer to the heart, using either a subxiphoid pocket location or positioning the generator pocket in an intrathoracic location, which we term the retrocostal approach. With the retrocostal approach, the generator and coils of redundant leads are positioned posterior to the rectus muscle at a location behind the lower margin of the rib cage.

The rationale for the retrocostal approach was to avoid the exposed nature of the epicardial leads as they traverse from the abdomen superiorly into the mediastinum and to leave the leads and device in a "protected" pocket behind the rib cage. We hypothesized that the retrocostal approach would reduce the rate of lead failure due to fracture. This study aimed to assess lead survival characteristics among our epicardial pacemaker patients to determine whether the retrocostal pocket location was associated with increased lead survival compared with the subrectus and subxiphoid pocket locations and to examine risk factors for epicardial lead failure in this patient population.

\section{Methods}

\section{Design and Subjects}

We undertook a retrospective chart review of all patients with epicardial pacemaker systems implanted or followed at Rady Children's Hospital-San Diego between January 1980 and May 2007. Institutional review board approval was obtained before data collection. Patients were identified by review of medical records and our surgical database. Transvenous pacemaker systems and leads placed prophylactically were excluded from the analysis. Patients whose devices were implanted outside our institution were included in the study when adequate follow-up evaluation, pocket location, and variables of their implanted devices were documented.

\section{Data Collection}

We reviewed all medical records in hard and soft copy for the purposes of our study. These included electronic databases, paper charts, and surgical and electrophysiological records. The demographic and clinical variables collected were date of birth, gender, height and weight at the time of the implantation and the latest follow-up evaluation, anatomic and electrophysiologic diagnosis, and number of prior operations. When patient height or weight were not available for a device implantation procedure, we used two to three points on the patient's plotted growth curve (National Center for Health Statistics 2000, 3rd to 97th percentile charts) and extrapolated the curve to determine the patient's approximate implant dimensions. The implantation procedure-related variables collected were pocket location (derived from the surgeon's operative notes and confirmed using radiography and follow-up records whenever possible), the implantation date, and the implanting surgeon. The lead-specific variables collected were the make and model of the lead (and associated manufacturing details such polarity, insulation material, steroid-eluting properties), lead tip location (epicardial or transmural-endocardial), lead chamber (atria or ventricle), lead functional characteristics (implant and latest follow-up capture threshold, sensing, and impedance), lead failure (yes/no), and lead failure type described in the following discussion.

\section{Definitions}

We defined a lead's lifetime from the implantation date to the date of documented lead failure, removal, or latest follow-up date within the study period. If the pocket location was changed and an existing lead reused, the lead was censored at the time of pocket relocation. When an apparently normally functioning lead was removed or replaced (elective replacement), the latest follow-up date was recorded, and the lead was censored. Other outcomes recorded included patient death, heart transplantation, abandonment of pacing system, patient lost to follow-up evaluation, or completion of the study period. Failure type was noted for all failed leads whenever possible and categorized as proven lead fracture by direct inspection or radiograph, pacing problems such as failure to capture or unacceptably high capture threshold, clinically significant sensing problems, or suspected lead fracture due to lead impedance or cause otherwise not specified.

\section{Surgical Technique}

The standard techniques for creation of subrectus and subxiphoid pacemaker pockets have been reviewed elsewhere [8]. The retrocostal approach is performed as follows. An entry into the left posterior rectus sheath is made near the lower margin of the sternotomy incision, and a pocket is developed within the rectus sheath. The upper margin of the rectus sheath is delimited by its attachment to the subcostal margin. This attachment is carefully dissected off the ribs to permit extension of the pocket cephalad, beyond and posterior to the subcostal margin. Care is taken to remain extrapleural in the cephalad extension of the pocket.

The pacemaker generator is positioned within the pocket so as to be almost entirely retrocostal. An anchoring suture secures the generator to the periosteum of the ribs to prevent it from migrating outside the protection of the overlying rib. The header of the generator, with lead attachments, is entirely posterior to the ribs, so the course of the leads never emerges 
from the protection of the overlying rib cage. This method is in contradistinction to the prior method of the rectus sheath pocket, in which the leads pass over the abdominal wall to course into the pericardial envelope (Fig. 1).

\section{Statistical Analysis}

For the primary outcome analysis, the patient cohort was divided into three groups based on the pocket location used (retrocostal, subxiphoid, or subrectus). Kruskal-Wallis one-way analysis of variance by ranks was used for testing equality of population medians among the three groups. Lead survival as a function of pocket location was plotted using Kaplan-Meier analysis. The resulting survival curves were assessed for statistical difference using the log-rank test. The chi-square test was used to test for an association between lead failure type and pocket location.

For our secondary outcome analysis, we tested candidate variables for correlation with lead failure in the entire cohort. Both patient- and lead-specific variables were examined. For other patient-specific variables, Cox proportional hazard analysis was performed using the patient as the unit of analysis and modeling on time to the first lead failure. Each patient was entered only once. For lead-specific variables, the lead was considered the primary unit of analysis. A patient could have more than one lead failure.

Multivariate analyses were performed using Cox proportional hazards, with an entry criteria of univariate $p$ value less than 2 . Confidence intervals (CI) at $95 \%$ are presented for hazard ratios in Cox regression. The statistical programming package of Stata/IC for Windows version 10 (StataCorp, College Station, TX, USA) was used for uni- and multivariate Cox proportional hazards analysis. All other statistical analyses were performed using SPSS, version 16 (SPSS Inc., Chicago, IL, USA).
A power analysis was conducted using Power and Precision 3.0 (Biostat Inc, 2001, Englewood, NJ, USA). For the described study design, sample size (number of leads), attrition rate ( 0$)$, alpha $(p \leq 0.05)$ and tails (2), and population effect size described earlier, the study had a power of $83 \%$ to yield a statistically significant result.

\section{Results}

\section{Patient Characteristics}

Our cohort consisted of 219 patients with a total of 620 leads that comprised the study sample. Of these patients, 107 were women, and 84\% (183/219) had structural congenital heart disease. The majority of the patients were young, with $45 \%$ younger than 3 years, and only $8 \%$ of the patients 18 years or older at the time of the first implantation. The predominant indication for pacing was thirddegree heart block.

The cohort was divided into three groups by pocket location. The majority of the patients had either a subrectus or retrocostal pocket location. Demographic data for our patient population were assessed for equivalence between groups. Age, gender, weight, height, implant body surface area, cardiac anatomy, pacemaker indication, and number of prior surgeries were not significantly different between the three groups. The follow-up period was longer in the subrectus pocket location group (Table 1).

\section{Lead Characteristics}

The median duration of lead follow-up assessment was 3.1 years $(n=620)$. The majority of leads were manufactured by Medtronic (Minneapolis, MIN) (442/620, 71\%),
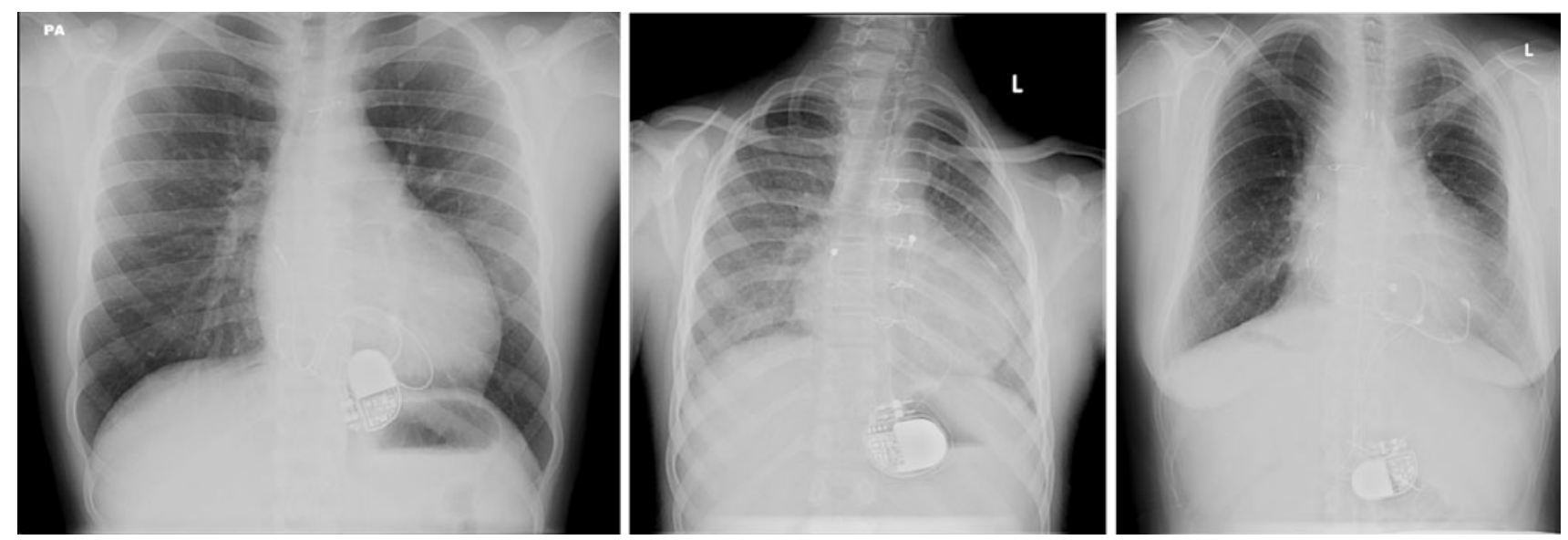

Fig. 1 Chest radiographs demonstrating pocket locations. The typical sites of epicardial pacemaker implantation are demonstrated from left to right: retrocostal, subxiphoid, and subrectus. Notably, the retrocostal location keeps all hardware within an intrathoracic location, whereas the subrectus and subxiphoid pacemaker pockets require that the pacemaker leads traverse the abdominal musculature 
Table 1 Patient demographics

\begin{tabular}{|c|c|c|c|c|c|}
\hline Variable & Subrectus & Subxyphoid & Retrocostal & Total & $p$ Value \\
\hline$n$ & 99 & 24 & 96 & 219 & - \\
\hline \multicolumn{6}{|l|}{ Demographic data (at first implant) ${ }^{\mathrm{a}}$} \\
\hline Female $(\%)$ & $49 \%$ & $58 \%$ & $46 \%$ & $49 \%$ & 0.541 \\
\hline Median age: years (range) & $3.08(0-30.04)$ & $6.59(0-37.84)$ & $4.27(0-39.51)$ & 3.62 & 0.140 \\
\hline Median follow-up period: years (range) & $5.32(0.02-22.75)$ & $3.53(0.02-14.61)$ & $2.77(0.04-14.40)$ & 3.69 & $<0.001$ \\
\hline Median weight: kg (range) & $11.9(2.0-95.4)$ & $18.1(2.5-64.1)$ & $15.9(2.0-87.5)$ & 14.0 & 0.168 \\
\hline Median height: cm (range) & $86(33-173)$ & $104.5(37-177)$ & $99(43-179)$ & 96 & 0.188 \\
\hline Median body surface area: $\mathrm{m}^{2}$ (range) & $0.527(0.15-2.03)$ & $0.732(0.17-1.75)$ & $0.658(0.15-1.98)$ & 0.611 & 0.204 \\
\hline Median no. of prior surgeries: $n$ (range) & $2(0-6)$ & $1(0-7)$ & $2(0-11)$ & 2 & 0.114 \\
\hline Principal cardiac diagnosis: $n(\%)$ & & & & & 0.397 \\
\hline Congenital structural heart disease & $85(85.9)$ & $19(79.2)$ & $79(82.3)$ & $183(83.6)$ & - \\
\hline Cardiomyopathy & $3(3.3)$ & $0(0)$ & $3(3.1)$ & $6(27.4)$ & - \\
\hline No structural heart disease & $8(8.1)$ & $5(20.8)$ & $14(17.7)$ & $27(12.3)$ & - \\
\hline Unknown & $3(3.3)$ & $0(0)$ & $0(0)$ & $3(1.6)$ & - \\
\hline Indication for device placement $(n)$ & & & & & 0.266 \\
\hline Arrhythmia, nonspecific (cardiac) & 1 & 0 & 1 & 2 & \\
\hline Atrial fibrillation & 0 & 0 & 1 & 1 & \\
\hline Atrial flutter & 4 & 1 & 4 & 9 & \\
\hline Bradycardia (sinus) & 3 & 1 & 3 & 7 & \\
\hline Functional disturbances after cardiac surgery & 0 & 0 & 1 & 1 & \\
\hline Heart block $1^{\circ}$ & 1 & 0 & 1 & 2 & \\
\hline Heart block $2^{\circ}$ type 1 Wenckebach & 0 & 2 & 4 & 6 & \\
\hline Heart block $2^{\circ}$ type 2 Mobitz & 4 & 2 & 5 & 11 & \\
\hline Heart block $3^{\circ}$ (acquired) & 38 & 10 & 25 & 73 & \\
\hline Heart block $3^{\circ}$ congenital & 7 & 1 & 15 & 23 & \\
\hline Junctional rhythm & 0 & 0 & 8 & 8 & \\
\hline Junctional tachycardia & 0 & 0 & 1 & 1 & \\
\hline Left bundle branch block & 0 & 0 & 1 & 1 & \\
\hline Multifocal atrial tachycardia & 0 & 0 & 1 & 1 & \\
\hline Sinus node dysfunction & 38 & 7 & 24 & 69 & \\
\hline Syncope & 1 & 0 & 0 & 1 & \\
\hline Unknown & 1 & 0 & 1 & 2 & \\
\hline Ventricular tachycardia & 1 & & & 1 & \\
\hline Total & 99 & 24 & 96 & 219 & \\
\hline Lead failure $^{\mathrm{b}}$ & $62(62)$ & $7(29)$ & $26(27)$ & $95(43)$ & $<0.001$ \\
\hline
\end{tabular}

Each patient is counted once in this analysis using first implantation information. Patients may have had more than one lead and more than one pocket location. The $p$ values were derived from Kruskal-Wallis tests for demographic data. Categorical data for principal cardiac diagnosis and indication for device placement were assessed with Pearson chi-square

${ }^{a}$ For continuous variables, median (range) is reported. For categorical variables the count $(n)$ is listed as well as the percentage within that pocket location subgroup $(\%)$

${ }^{\mathrm{b}}$ No. of patients who experienced one or more lead failures during the study period

and $55 \%$ of the leads used were steroid eluting. Most of the leads were silicone $(77 \%)$, and slightly more than half of the leads used a "screw-in" fixation mechanism. As outlined in Table 2, manufacturer, insulation material, steroid elution, polarity, and fixation methods differed between the groups by pocket location $(p=0.01)$.

\section{Procedural Characteristics}

A total of 284 leads were placed in 99 patients using the subrectus pocket location. The retrocostal approach was used for 274 leads in 96 patients. For the remainder, a subxiphoid pocket location was used (Tables 1,2$)$. The 
Table 2 Lead characteristics by pocket location

\begin{tabular}{|c|c|c|c|c|c|}
\hline Variable & $\begin{array}{l}\text { Subrectus } \\
n(\%)^{\mathrm{a}}\end{array}$ & $\begin{array}{l}\text { Subxyphoid } \\
n(\%)\end{array}$ & $\begin{array}{l}\text { Retrocostal } \\
n(\%)\end{array}$ & Total & $p$ Value \\
\hline$n$ & 284 & 62 & 274 & 620 & - \\
\hline Manufacturer: $n(\%)$ & & & & & $<0.001$ \\
\hline Medtronic & $205(72.2)$ & 57 (91.9) & $180(65.7)$ & $442(71.3)$ & - \\
\hline Guidant (CPI) & $15(5.3)$ & $1(1.6)$ & $86(31.4)$ & $102(16.5)$ & - \\
\hline St. Jude Medical & $0(0)$ & $0(0)$ & $0(0)$ & $0(0)$ & - \\
\hline Intermedics & $37(13.0)$ & $2(3.2)$ & $1(0.4)$ & $40(6.5)$ & - \\
\hline Unknown & $27(9.5)$ & $7(11.3)$ & $2(0.7)$ & $36(5.8)$ & - \\
\hline Steroid-eluting: $n(\%)$ & & & & & $<0.001$ \\
\hline Steroid-eluting & $91(32.0)$ & $47(75.8)$ & $206(75.2)$ & $344(55.5)$ & - \\
\hline Non-steroid-eluting & $166(58.5)$ & $13(21.0)$ & $61(22.2)$ & $240(38.7)$ & - \\
\hline Unknown & $27(9.5)$ & $2(3.2)$ & $7(2.6)$ & $36(5.8)$ & - \\
\hline Polarity: $n(\%)$ & & & & & $<0.001$ \\
\hline Bipolar & $46(16.2)$ & $16(25.8)$ & $172(62.8)$ & $234(37.7)$ & - \\
\hline Unipolar & $211(74.3)$ & $44(71.0)$ & $95(34.7)$ & $350(56.5)$ & - \\
\hline Unknown & $27(9.5)$ & $2(3.2)$ & $7(2.6)$ & $36(5.8)$ & - \\
\hline Insulation material: $n(\%)$ & & & & & $<0.001$ \\
\hline Silicone & $181(63.7)$ & $59(95.2)$ & $247(90.1)$ & $480(77.4)$ & - \\
\hline Polyurethane & $16(5.6)$ & $1(1.6)$ & $17(6.2)$ & $34(5.5)$ & - \\
\hline Unknown & $27(9.5)$ & $2(3.2)$ & $7(2.6)$ & $36(5.8)$ & - \\
\hline Fixation mechanism: $n(\%)$ & & & & & $<0.001$ \\
\hline Screw-in & $132(46.5)$ & $11(17.7)$ & $206(75.2)$ & $349(56.3)$ & - \\
\hline Sew-on & $68(23.9)$ & $43(69.4)$ & $58(21.2)$ & $169(27.3)$ & - \\
\hline Stab-in & $57(20.0)$ & $6(9.7)$ & $3(1.1)$ & $66(10.7)$ & - \\
\hline Unknown & $27(9.5)$ & $2(3.2)$ & $7(2.6)$ & $36(5.8)$ & - \\
\hline
\end{tabular}

Each lead is used as the unit of analysis. Patients may have more than one lead. If the pocket location is changed and a functioning lead is left in situ, the lead is censured at the time of pocket change. Due to the study's constraints, with access limited to only our in-house medical records, we were unable to obtain every variable for every lead in our study. Analyses were conducted with unknowns as missing values, which did not change the $p$ values in our chi-square tests. Categorical data for the variables were assessed with Pearson chi-square. Lead fracture grouping includes proven lead fracture, suspected lead fracture, and lead impedance

a $\%$ indicates the percentage of leads within that implantation location subgroup

implanting surgeon was recorded for 583 of 620 leads (94\%). A total of 11 surgeons implanted one or more of the 620 leads analyzed. Of these 11 surgeons, 3 accounted for $83 \%(518 / 620)$ of the procedures. Most of the retrocostal implants $(84 \%, 230 / 274)$ were performed by a single surgeon.

\section{Lead Failure}

Overall, 43\% (95/219) of the patients experienced one or more lead failures during a median follow-up period of 3.7 years, and $28 \%(173 / 620)$ of the leads failed during a mean follow-up period of 3.1 years. The estimated lead survival was $93 \%$ at 2 years and $83 \%$ at 5 years. The majority of the leads failed due to pacing problems $(54 \%$, 93/173) (e.g., high pacing thresholds), followed by lead fracture $(31 \%, 53 / 173)$ and sensing problems (14\%, $24 / 173)$. When divided into groups by pocket location, the majority of lead failures were seen in the subrectus group (116/173). Overall, $40 \%$ of the leads using this pocket location failed compared with $16 \%$ and $17 \%$ of the leads placed in subxiphoid and retrocostal locations, respectively $(p=0.001)$. However, when adjustment was made for length of follow-up evaluation, the rates of failure by implant location did not differ significantly (Fig. 2, Table 3). In general, chi-square analysis showed no significant differences of lead failure cause by implant site (Fig. 3). There were no statistical differences between lead failure rates and the implanting surgeon.

\section{Risk Factors for Lead Failure}

Consistent with the Kaplan-Meier analysis, a univariate Cox proportional hazard analysis failed to show any differences between implant location and risk of failure (Table 4). This variable was tested using both a 
Fig. 2 Kaplan-Meyer survival curve for epicardial pacemaker leads by pocket location. Cumulative lead longevity, defined as freedom from lead failure for any reason, does not differ between retrocostal, subrectus, and subxiphoid pacemaker pocket locations $(p=0.491$, Mantel-Cox $)$

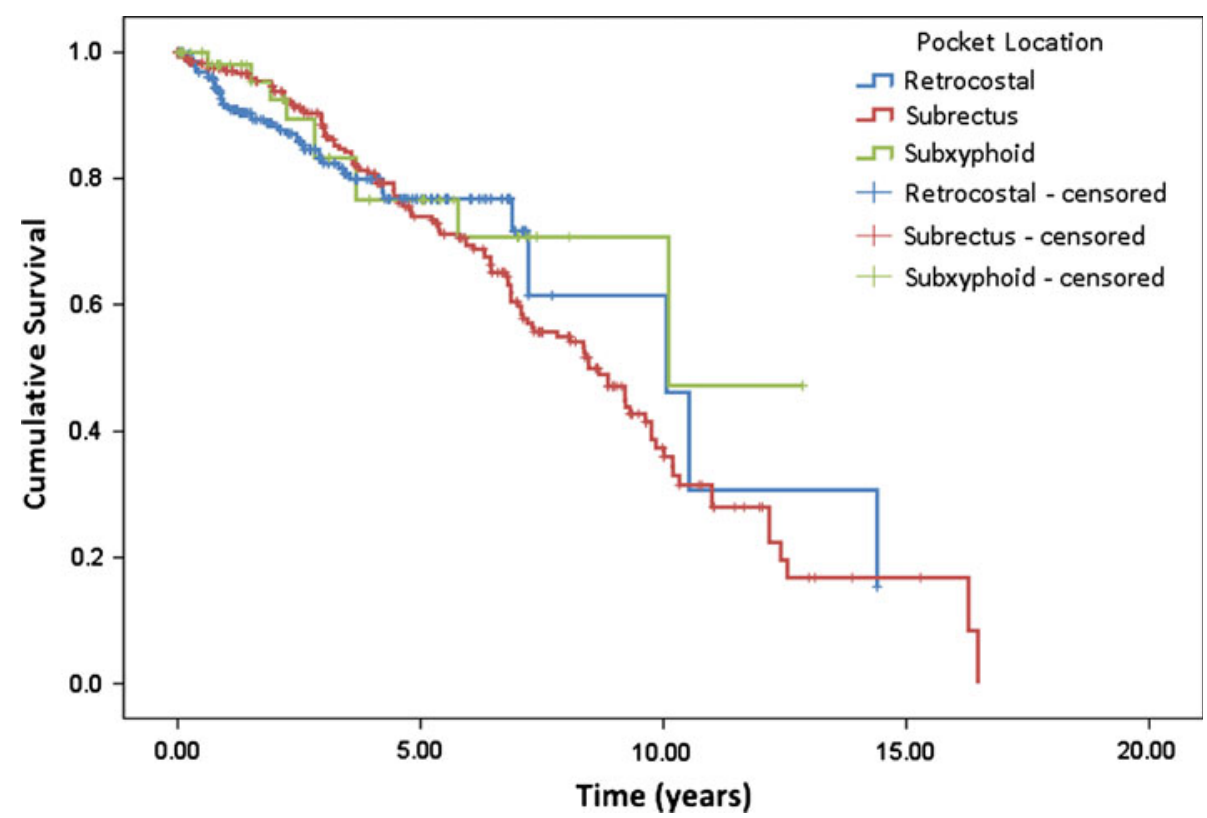

Table 3 Lead failure by pocket location

\begin{tabular}{|c|c|c|c|c|c|}
\hline Variable & $\begin{array}{l}\text { Subrectus } \\
n(\%)^{\mathrm{a}}\end{array}$ & $\begin{array}{l}\text { Subxyphoid } \\
n(\%)\end{array}$ & $\begin{array}{l}\text { Retrocostal } \\
n(\%)\end{array}$ & Total & $p$ Value \\
\hline$n$ & 284 & 62 & 274 & 620 & - \\
\hline Lead failure & $116(40.8)$ & $10(16.1)$ & $47(17.2)$ & $173(27.9)$ & 0.002 \\
\hline Cause of lead failure ${ }^{a}$ & - & - & - & - & 0.194 \\
\hline Lead fracture & $38(32.8)$ & $3(30)$ & $12(25.5)$ & $53(30.6)$ & - \\
\hline Pacing problems (NOS) & $62(53.5)$ & $7(70)$ & $24(51.1)$ & $93(15.0)$ & - \\
\hline Sensing problems (NOS) & $13(11.2)$ & $0(0)$ & $11(23.4)$ & $24(13.9)$ & - \\
\hline Unknown & $3(2.6)$ & $0(0)$ & $0(0)$ & $3(1.7)$ & - \\
\hline No lead failure & $168(59.2)$ & $52(83.9)$ & 227 (82.9) & $447(72.1)$ & - \\
\hline
\end{tabular}

${ }^{a}$ The cause of lead failure is not shown to be statistically different when stratified by lead failure versus nonfailure $(p=0.194$, Pearson chisquare). See Fig. 3 for graphic representation

patient- and lead-specific analysis. Other candidate variables were tested, with none proving a significant relation to risk of failure. The patient-dependent variables included number of prior surgeries, age at first implantation, size, and presence of congenital heart disease. The lead-specific variables included brand, steroid elution, insulation material, fixation mechanism, and polarity.

\section{Discussion}

Previous studies have demonstrated an increased risk for failure of epicardial leads versus transvenous pacing systems. However, epicardial lead systems remain the technique of choice for patients who are either too small or possess contraindications to standard transvenous lead placement.
This study, the largest epicardial lead survival study to date, aimed to determine whether the risk of lead failure could be modified by pocket location, specifically by comparing lower rectus versus subxiphoid versus implantation behind the lower costal margin (retrocostal). Despite analysis of 620 leads in 219 patients over a median followup period longer then 3 years, we were unable to show any statistically significant benefit of one pocket location over another. Secondary analysis of a number of both patientand lead-specific variables also failed to identify any predictors of lead failure.

We were unable to demonstrate a statistically significant advantage of the retrocostal pocket location over other pocket locations in terms of lead fracture prevention. Qualitatively, however, the data (Fig. 3) suggest that lead failure by this mechanism appears to be less frequent with the retrocostal implantation technique. Although admittedly 
Fig. 3 Bar graph showing the cause of lead failure by pocket location expressed as the proportion of total lead failures. When lead failure is stratified by cause, groups do show statistical differences based on their epicardial pacemaker pocket location (retrocostal vs subrectus vs subxiphoid; $p=0.194$, Pearson chi-square)

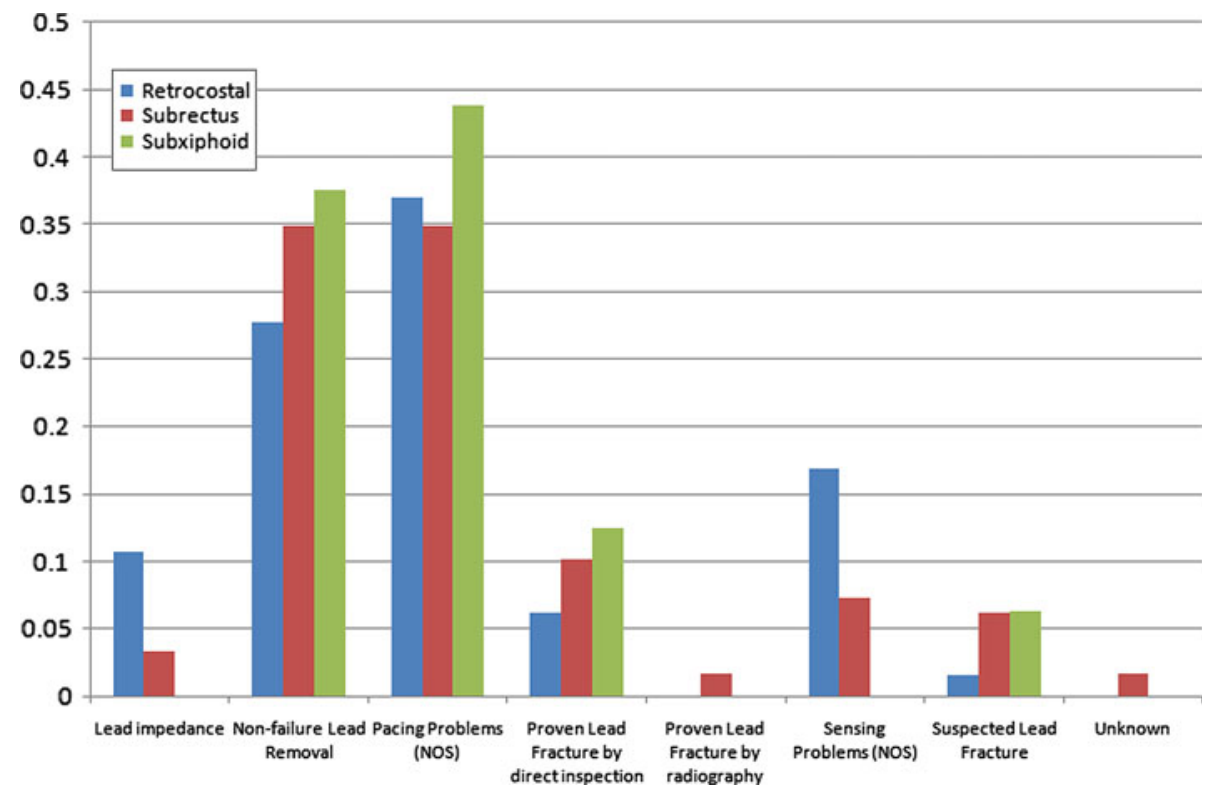

Table 4 Risk factors for lead failure (univariate analysis)

\begin{tabular}{lllll}
\hline Variable & HR & $p$ Value & $\begin{array}{l}\text { Lower } \\
\text { CI }\end{array}$ & $\begin{array}{l}\text { Upper } \\
\text { CI }\end{array}$ \\
\hline Patient variables $^{\mathrm{a}}$ & & & & \\
Pocket location (retrocostal) & 1.06 & 0.807 & 0.66 & 1.71 \\
No. of prior surgeries $>2$ & 1.47 & 0.067 & 0.97 & 2.24 \\
Age at first implant $<12$ years & 0.93 & 0.778 & 0.55 & 1.56 \\
Congenital heart disease & 1.67 & 0.146 & 0.84 & 3.32 \\
Linear growth rate $\geq 15 \mathrm{~cm} /$ & 0.82 & 0.391 & 0.52 & 1.29 \\
year & & & & \\
Height at first implant & 1.41 & 0.146 & 0.89 & 2.25 \\
$\leq 70$ cm & & & & \\
Weight at first implant $\leq 8 \mathrm{~kg}$ & 1.31 & 0.256 & 0.82 & 2.07 \\
Age at first implant $\geq 18$ years & 1.03 & 0.944 & 0.45 & 2.39 \\
Age at first implant & 1.20 & 0.533 & 0.68 & 2.13 \\
12-18 years & & & & \\
Lead variables & & & & \\
Pocket location (retrocostal) & 1.014 & 0.938 & 0.71 & 1.44 \\
Lead manufacturer: & 0.740 & 0.062 & 0.54 & 1.02 \\
Medtronic & & & & \\
Steroid-eluting & 0.833 & 0.307 & 0.59 & 1.18 \\
Insulation material: silicone & 1.02 & 0.908 & 0.73 & 1.41 \\
Fixation mechanism: sew-on & 1.02 & 0.889 & 0.69 & 1.51 \\
Polarity: bipolar & 0.870 & 0.498 & 0.58 & 1.31 \\
\hline
\end{tabular}

$H R$ hazard ratio, $C I$ confidence interval

${ }^{\text {a }}$ Each patient is counted once, modeled on time to first lead failure. Some patients experienced more than one lead failure

b Each lead is counted as a unique entity in this analysis

not rigorously supported by the data in this report, it is the authors' practice for patients with a retrocostal implant who are not pacemaker dependent to liberate them from the contact sports restrictions that typically accompany the alternative implant locations.

The relative surgical risk of the various implantation techniques was not addressed in this study. The experience of the surgeon performing the majority of the retrocostal implantations indicates that the various implant locations are comparable in terms of associated risks. At the primary study institution, all epicardial generator changes were performed by cardiothoracic surgeons, although this is an institutional bias and does not reflect the suitability of these procedures for an appropriately trained electrophysiologist. Similar to the subxiphoid pocket location, generator change or removal of a device in the retrocostal position can be performed by reopening the subxiphoid incision and dissecting through the largely avascular planes defined by the pseudointima surrounding the generator. This does not require a sternotomy. Generator changes or removals, unless performed in combination with larger cardiac procedures, typically do not require an inpatient hospital stay.

Among leads, there were significant differences in manufacturer, steroid elution, polarity, insulation material, and fixation method when compared by group. We speculate that the differences between groups result from their date of implantation. Our subrectus implantations were the earliest epicardial surgeries performed at our center, whereas the retrocostal and subxiphoid implantations were the most recent.

During the study period, pacemaker leads were engineered with newer insulation materials, bipolarity, and steroid elution in attempts to improve their longevity [3]. Yet with all this, we still were impressed with the consistency in the rate of lead failure across groups regardless of lead characteristic or pocket location. 
Fig. 4 Kaplan-Meyer survival curve for epicardial pacemaker leads by (non)steroid elution. For all leads for all pacemaker pocket locations, comparison of steroid-eluting leads with nonsteroid-eluting leads shows no significant difference in lead longevity $(p=0.244$, MantelCox)

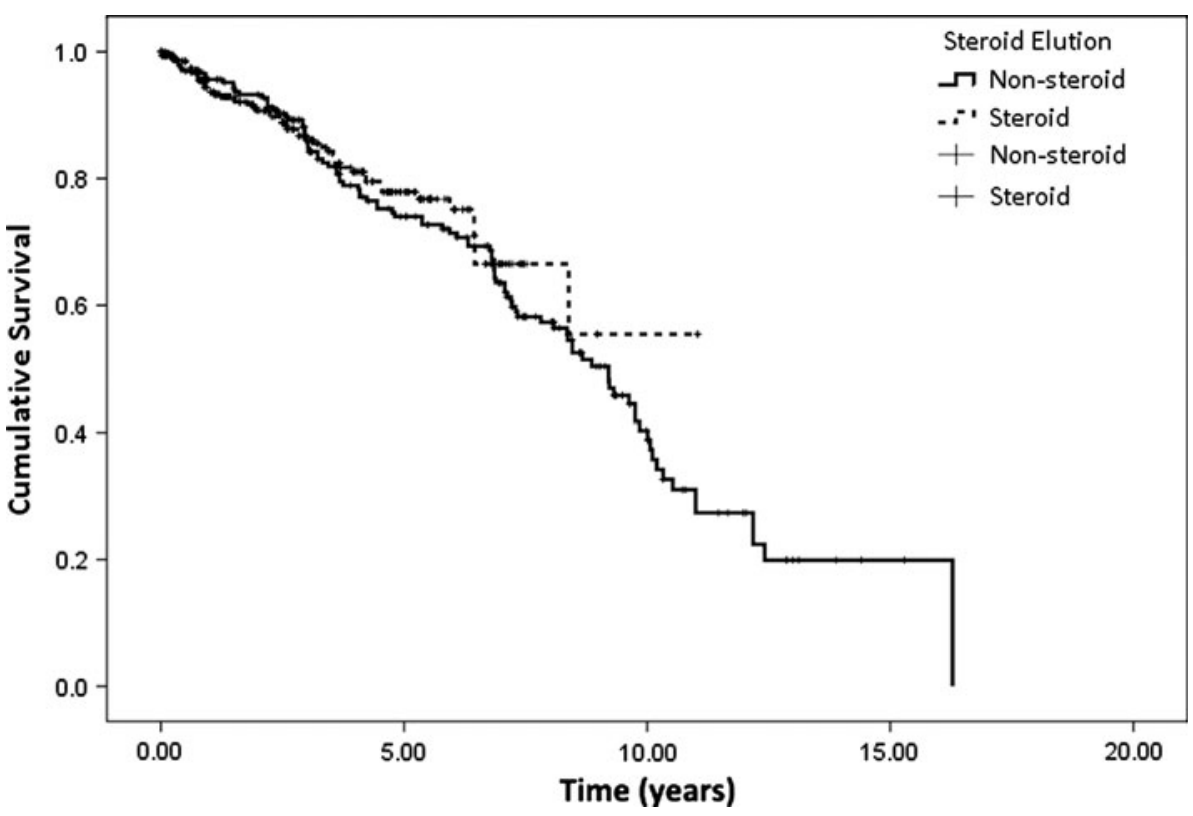

Previous lead survival studies have demonstrated remarkable consistency in estimated lead survival despite a broad period and range of techniques covered. For example, Fortescue et al. [6] undertook a retrospective analysis of all pediatric pacemaker placements between 1980 and 2002 at a single pediatric hospital. They identified 1,007 leads in 497 subjects, 523 of which were epicardial leads. Consistent with the practices at other centers, epicardial leads were more often used in younger children and those with congenital heart disease. These two factors were found in both single and multivariate analysis to be independent correlates of reduced lead longevity. Similarly, epicardial placement also was an independent correlate with lead failure. As in our study, the steroid-eluting versus noneluting leads showed no difference in lead longevity for epicardial devices (Fig. 4). Although the 5-year survival rate for their epicardial leads approached $85 \%$, compared with approximately $75 \%$ in our study, the median age at implantation was 9 years compared with 3.62 years in our study.

Smerup et al. [12] undertook a prospective study attempting to quantify risk among 61 patients. Germane to this discussion, they too found that the epicardial leads, low age at implantation, and high risk-adjusted congenital heart surgery (RACHS) score were significant predictors for early device mortality. Approximately $50 \%$ of all their patients had their first device 5 years after implantation.

Cohen et al. [2] provides another comparison for our study. Between 1983 and 2000, these authors had 123 patients with 207 epicardial leads. The median age at implantation was 4.1 years, and $84 \%$ of the patients had underlying structural congenital heart disease. The 5-year lead survival rate among this population was $74 \%$. Similar failure rates were seen in Epstein et al. [5], with 33 epicardial patients and a $60 \%$ lead survival at 6 years; Dodge-Khatami et al. [4], with 41 children and an $86 \%$ lead survival at 5 years; and Thomson et al. [13], with 326 patients and a lead survival of $50 \%$ to $76 \%$ at 5 years.

\section{Study Limitations}

Because our study was retrospective, our analysis was limited in scope. We were not able to control for surgeon technique or device preference. Similarly, due to the technological evolution of pacemakers and leads, lead characteristics significantly differed by implant location. For example, the subrectus group included more nonsteroid-eluting leads than the subxiphoid or retrocostal group. Nevertheless, we were surprised to see that not only was the null hypothesis not disproven, but our risk model also was statistically not significant. It would appear that our pediatric epicardial pacemaker population, with its low median age, preponderance of congenital structural heart disease, and multiple surgeries, does not accommodate itself to an internal risk model because the vast majority of patients already possess the known risk factors for early lead failure.

\section{Conclusions}

Based on the outcomes of this study and a review of the current literature, we conclude that the retrocostal approach is neither superior nor inferior to the subrectus or subxiphoid approach in terms of lead longevity and freedom 
from failure. Identifying modifiable risk factors that may have an impact on epicardial lead survival remains challenging.

Acknowledgments We thank the Rady Children's Heart InstituteSan Diego for supporting this research endeavor. This project was made possible through funding from the NIH Predoctoral Clinical Research Training Program, no. T32 RR023254.

Open Access This article is distributed under the terms of the Creative Commons Attribution Noncommercial License which permits any noncommercial use, distribution, and reproduction in any medium, provided the original author(s) and source are credited.

\section{References}

1. Antretter H, Colvin J, Schweigmann U, Hangler H, Hofer D, Dunst K (2003) Special problems of pacing in children. Indian Pacing Electrophysiol 3:23-33

2. Cohen MI, Rhodes LA, Spray TL, Gaynor JW (2004) Efficacy of prophylactic epicardial pacing leads in children and young children. Ann Thorac Surg 78:197-202

3. Cutler NG, Karpawich PP, Cavitt D, Hakimi M, Walter HL (1997) Steroid-eluting epicardial pacing electrodes: six-year experience of pacing thresholds in a growing pediatric population. Pace 20:2943-2948

4. Dodge-Khatami A, Kadner A, Dave H, Rahn M, Prêtre R, Bauersfeld U (2005) Left heart atrial and ventricular epicardial pacing through a left lateral thoracotomy in children: a safe approach with excellent functional and cosmetic results. Eur J Cardiothorac Surg 28:541-545

5. Epstein MR, Walsh EP, Saul JP, Triedman JK, Mayer JE, Gamble WJ (1998) Long-term performance of bipolar epicardial atrial pacing using an active fixation bipolar endocardial lead. Pace 21:1098-1104

6. Fortescue E, Berul C, Checchin F, Walsh E, Triedman J, Alexander M (2004) Patient, procedular, and hardware factors associated with pacemaker lead failures in pediatrics and congenital heart disease. Heart Rhythm 1:150-159

7. Gillette PC, Zeigler VL, Winslow AT, Kratz JM (1992) Cardiac pacing in neonates, infants, and preschool children. Pace 15:2046-2049

8. Maginot KR, Mathewson JW, Bichell DP, Perry JC (2000) Applications of pacing strategies in neonates and infants. Prog Pediatr Cardiol 11(1):65-75

9. Sachew JS, Vazquez-Jimenez JF, Schöndube FA, Daebritz SH, Dörge H, Mühler EG, Messmer BJ (2000) Twenty years experience with pediatric pacing: epicardial and transvenous stimulation. Eur J Cardiothorac Surg 17:455-461

10. Silka MJ, Bar-Cohen Y (2006) Pacemakers and implantable cardioverter-defibrillators in pediatric patients. Heart Rhythm 3:1360-1366

11. Silvetti MS, Drago F, Grutter G, De Santis A, Di Ciommo V, Ravà L (2006) Twenty years of paediatric cardiac pacing: 515 pacemakers and 480 leads implanted in 292 patients. Europace 8:530-536

12. Smerup M, Hjertholm T, Johnsen SP, Pedersen AK, Hansen PS, Mortensen PT, Hansen OK, Hjortdal V (2005) Pacemaker implantation after congenital heart surgery. Eur J Cardiothorac Surg 28:61-68

13. Thomson J, Blackburn M, Van Doorn C, Nicholls A, Watterson K (2004) Pacing activity, patient and lead survival over 20 years of permanent epicardial pacing in children. Ann Thoarac Surg 77:1366-1370

14. Warner KG, Halpin DP, Berul CI, Payne DD (1999) Placement of a permanent epicardial pacemaker in children using a subcostal approach. Ann Thorac Surg 68:173-175 